International Journal of Multidisciplinary Research AND ANALysis

ISSN(print): 2643-9840, ISSN(online): 2643-9875

Volume 04 Issue 12 December 2021

DOI: 10.47191/ijmra/v4-i12-09, Impact Factor: 6.072

Page No.- 1833-1836

\title{
Formation and Analysis of Synonyms in English
}

\section{Durdona Rashidova}

Student, Uzbekistan State World Languages University Tashkent, Uzbekistan

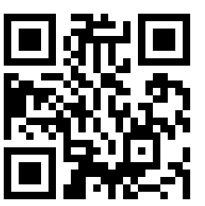

ABSTRACT: This article discusses the formation and analysis of synonyms in English. For the implementation of the communicative and expressive functions of language, accuracy, expressiveness, a large semantic variety of vocabulary, the ability to strictly differentiate concepts, convey more and more subtle shades of thought and feeling are necessary. The need to differentiate the concept, to express the shades of thoughts and feelings, brings synonyms to life.

KEYWORDS: formation, analysis, English, synonym, language, context, translation, dictionary, difficulties, vocabulary, speech, agreement, words, meaning, definition, denotations.

\section{INTRODUCTION}

English is one of the languages in which such a phenomenon as synonymy is extremely pronounced. In terms of the number of words similar in meaning, it is significantly ahead of most European languages. At the same time, it is this phenomenon that can lead to difficulties with the correct use of vocabulary in speech, as well as with translation.

Over the past decade, synonyms have been analyzed with a significant number of large foreign and regional studies. In the field of lexicography on the problem of synonyms in the English language, a significantly revised edition of the well-known Webster's Dictionary of Synonyms should be especially noted, where the preface says that synonyms are always two or more words that have the same basic meaning and therefore are interpreted in the same way. Synonyms are usually distinguished by additional implication or connotation - either by idiomatic or contextual use, the only satisfactory criterion for synonymy indicated in the preface - is the agreement of words in detonations, but this agreement is rarely so complete, so that it gives synonyms that are absolutely identical in meaning; the definition of synonymy in Webster's dictionary indirectly means that words that are absolutely identical in meaning or absolute synonyms are in one way or another different from each other (synonyms can be defined in the same terms up to a certain point).

\section{THE MAIN FINDINGS AND RESULTS}

In Webster's Great Encyclopedic and Explanatory Dictionary, synonyms are defined as words of one part of speech that have the same or almost the same basic or generic meaning and differ only in connotation; words that have basically the same interpretation. Words that coincide in at least one of their senses; words or expressions that can replace each other without violating the rules of the language or the meaning of the sentence.

According to the opinion of a relatively small group of linguists, only words that are identical in meaning should be considered synonyms. According to other researchers, only lexical units that are close, similar, but not identical in meaning are genuine synonym amines. And finally, the most common point of view on synonyms is, as it were, a compromise, since synonyms mean both close and identical lexical units. Most synonymous dictionaries in our country and abroad are based on the latter principle.

The improvement of the language occurs not only in the form of quantitative enrichment, although the latter is of great importance and goes on continuously, so that the influx of words in a living language is always much more intense. For the implementation of the communicative and expressive functions of language, accuracy, expressiveness, a large semantic variety of vocabulary, the ability to strictly differentiate concepts, convey more and more subtle shades of thought and feeling are necessary. The need to differentiate the concept, to express the shades of thoughts and feelings, brings synonyms to life.

In synonyms, a more subtle differentiation of a concept is fixed, a refinement of the sign or degree of a sign of a concept, the nuances of the speaker's attitude to the subject of speech, the richness of the experience of the people to whom 


\section{Formation and Analysis of Synonyms in English}

the language belongs. The study of synonymy involves the consideration of words in their connection and correlation with other words of the language that are close to them in meaning.

The term "synonym" comes from the Greek word synonymos, which means the same name. This is the name for words that are different in sound, but coincide or very close in one or more of their meanings. Synonyms are single-field categorically identical vocabulary units that coincide in size in one or more vocabulary meanings. For example: semantics and semasiology, language and linguistics, secret and mystery, experience and experiment, bold and brave, car and automobile, astronaut and cosmonaut, to end and to finish, to start and to begin, jail and prison, etc. Synonyms refer to the same class of objects. The same objects acquire two names by chance or by logical necessity: each word characterizes the object differently.

When in lexicology they talk about synonyms, they mean and compare the dictionary meanings of words. Due to the generality of one or several of their meanings, synonyms are, within certain limits, interchangeable. Let's consider an example: The bright sunlight of an April morning woke her up. There was breakfast with her parent- their half amused and puzzled faces across the fable, wandering what could be this secret that made her eyes so bright.

The word appears here twice. In the second case, despite the fact that it is used in a figurative sense, it could be replaced with synonymous words: brilliant, radiant beaming, but only in the second. The combination of the same adjectives in the first sentence with a word, although it does not cause a distortion of the meaning, does not sound very familiar, since usually these words define not light, but the source of light. Thus, a synonymous substitution is possible only within certain limits, and within these limits, synonyms can differ significantly both in meaning and in use.

Therefore, for both a language researcher and a teacher, it is important to consider synonyms not so much as a word that can replace each other, but as a word that clarifies the thought and attitude to what is being expressed. The work on synonyms in the process of teaching a language should reveal not only the correspondence, but also the differences between them. These differences may relate to additional meanings, stylistic characteristics and usage in combination with certain words. The impossibility of complete interchangeability of synonyms also depends on the fact that words in a language are polysemantic and the semantic structure of one of the elements of a synonymous group never completely coincides with the semantic structure of another. The problem of synonymy is thus closely related to the problem of ambiguity. Two or more words can be synonymous in one or more meanings of the words bright and brilliant can be synonyms in their direct meaning - a bright star, and brilliant star and figuratively - a bright scholar, a brilliant scholar, but in a figurative meaning the second word conveys a higher degree of trait.

In the literature on synonymy known to us, the definitions of synonyms are mainly represented by sets of the following features:

1) The concept of community or their correlation with one concept;

2) Correlation with one denotation;

3) Identity or closeness in meaning;

4) The identity of words or elements of their semantic structure;

5) Similarity and closeness of individual meanings of words;

6) The generality of distribution;

7) Generality of compatibility;

In each individual meaning of the word, they are distinguished: material meaning (reflecting the totality of essential features of an object or phenomenon), shades of meaning or additional meanings that reflect accompanying ideas and emotional and stylistic coloring. For synonyms, the first must be the same. Calling the same phenomenon of reality, expressing one concept, synonyms emphasize in it various additional features that convey additional connections with the environment, its various sides, illuminates it from different points of view, express stylistic differences and thus enrich the vocabulary.

In the group of synonyms with the real meaning of courage: boldness, valor, gallantry, prowess, mettle, dauntlessness, grit, guts, we observe differences in accompanying representations, as well as stylistic differences.

Courage-the most common word;

Boldness - means courage and desire for danger, self-confidence, sometimes audacity;

Valor - personal courage, mainly military;

Prowess - also, but not necessarily a combination with success, victory;

Mettle - Contains an accompanying view of tenacity and endurance;

Gallantry - implies effective beautiful courage, chivalry.

The grammatical rules for using synonymous words can also be different. For example: also and too mean the same or also, but the adverb also is placed in front of the word to which it refers, and too in this meaning is placed at the end of the sentence; before the word being defined, too means too much. As a rule, synonyms refer to one part of speech, although, as an 


\section{Formation and Analysis of Synonyms in English}

exception, words belonging to different parts of speech can also be combined into a synonymous group. For example: the adjective breathless as synonyms corresponds to the participle puffing and panting and the prepositional phrase out of breath, and in a figurative meaning it is formed, from the second participle - astonished.

One should not think that the appearance of borrowed words is the only reason for the formation of synonyms in the language, although as a result of the peculiarities of the historical development of the English language, borrowings played a very large role in the development of its vocabulary. However, synonyms can also arise as a result of word formation by affixation, by conversion, by word composition, as a result of the emergence of stable phrases, etc.

With all the number of such cases, one should pay attention to the fact that, to a much greater extent than borrowings, English words are characterized by semantic flexibility, which ensures their greater stability in the language. They remain in the language as they begin to denote new concepts, sometimes very far from the original ones: in dwelling hotel; buxom obedient pretty; or they get new values, while simultaneously preserving the main old values, for example: hand while maintaining the main value hand, it gets the value worker and has become, thus, synonymous with the word worker. The semantic mobility of the verb in English is ensured by its compatibility with the so-called postpositions. Even in those cases when a foreign-language verb has firmly entered the English language and seems to be the main word for expressing a given concept, there is a synonym for it - some Germanic primordial or Scandinavian verb of broad semantics with a postposition: to return - to bring back, to educate - to bring up, to visit - to call on; to call at, to quarrel - to fall out, to betray - to give away, to explode - to go off.

It is well known the prevalence in the English language, especially in its colloquial style, of verb phrases synonymous with verbs, but differing from them in terms of species characteristics and stylistic coloring:

$\begin{array}{ll}\checkmark & \text { to laugh-to give laugh } \\ \checkmark & \text { to walk-to have a walk } \\ \checkmark & \text { to smoke-to have a smoke } \\ \checkmark & \text { to fasten-to make fast } \\ \checkmark & \text { to love-to fall in love } \\ \checkmark & \text { to sour-to turn sour }\end{array}$

As a result of word formation by affixation, we have obtained such synonymous pairs as: Undaunted - dauntless fearless, changeable-changeful - changeable, undefended - defenseless, sincerity -cincereness - sincerity, anxiety-anxiousness concern, affectivity - effectiveness - efficiency, middle - midst - average.

A large number of synonyms are formed as a result of the widespread use of abbreviations in modern English:

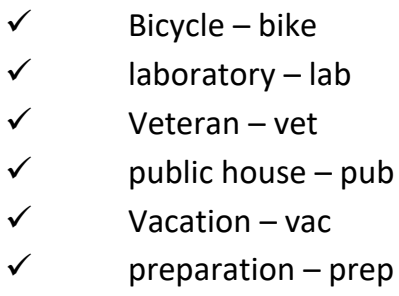

\section{CONCLUSION}

In conclusion, synonyms, therefore, are called words that sound differently related to one part of speech, having one or more similar meanings, which, expressing one concept, may differ in additional shades of meaning (expressing various additional features of a concept or accompanying representations, or a different degree of a feature), emotional or stylistic coloring, use and compatibility with other words of free and stable phrases.

\section{REFERENCES}

1) Puncevič, K. (2016). Patterns of semantic change in formation of English synonyms (Doctoral dissertation, Lietuvos edukologijos universitetas).

2) Grieve, J., Nini, A., \& Guo, D. (2017). Analyzing lexical emergence in modern american english online 1. English Language \& Linguistics, 21(1), 99-127.

3) Duda, B. (2015). The productivity of word-formation among selected Modern English synonyms of prostitute in an onomasiological method of research. SKASE Journal of Theoretical Linguistics, 12(1).

4) Bilynskyi, M. (2007). SYNONYMOUS STRINGS LENGTH AND CONSTITUENTS'PLACEMENT IN ENGLISH DEVERBAL WORDFORMATION: THE PHYSICIST'S CONTRIBUTION TO DIACHRONIC LEXICOLOGY. Journal of Physical Studies, 11(1), 6-21.

5) Bajburina, R. Z., \& Sergeeva, E. N. (2021). ABOUT THE PROBLEM OF DIFFERENTIATION OF MEANINGS OF THE SYNONYMS BY THE EXAMPLE OF THE ENGLISH VERBS OF POSITIVE ASSESSMENT. Russian Linguistic Bulletin, (1 (25)), 22-24. 


\section{Formation and Analysis of Synonyms in English}

6) NUHIU, M. (2011). BILINGUAL SYNONYMS IN ENGLISH AND ALBANIAN. Academic Days of Timişoara: Language Education Today, 183.

7) Bagirova, S. (2021). ARTISTIC LITERATURE AS A SOURCE OF FORMATION OF CONCEPTUAL SYNONYMS AND METAPHORS. Russian Linguistic Bulletin, (2 (26) 2021), 121-125.

8) Mühleisen, S. (2010). Heterogeneity in word-formation patterns: A corpus-based analysis of suffixation with-ee and its productivity in English (Vol. 118). John Benjamins Publishing.

9) Lipka, L. (2002). English lexicology: Lexical structure, word semantics \& word-formation (Vol. 941, No. 8105). Gunter Narr Verlag.

10) Schotter, E. R. (2013). Synonyms provide semantic preview benefit in English. Journal of Memory and Language, 69(4), 619-633.

11) DiMarco, C., Hirst, G., \& Stede, M. (1993, March). The semantic and stylistic differentiation of synonyms and nearsynonyms. In AAAI Spring Symposium on Building Lexicons for Machine Translation (Vol. 1, pp. 114-121).

12) Krawczak, K. (2014). Shame and its near-synonyms in English: A multivariate corpus-driven approach to social emotions. InI. Novakova, P. Blumenthal, \& D. Siepmann (Eds.), Les émotions dans le discours/Emotions in discourse, 8394.

13) Petcharat, N., \& Phoocharoensil, S. (2017). A Corpus-Based Study of English Synonyms: Appropriate, Proper, and Suitable. LEARN Journal: Language Education and Acquisition Research Network, 10(2), 10-24.

14) Crabb, G. (2017). Routledge Revivals: Crabb's English Synonyms (1916): Arranged Alphabetically with Complete Cross References Throughout. Routledge.

15) Fernald, J. C. (1896).... English Synonyms and Antonyms, with Notes on the Correct Use of Prepositions: Designed as a Companion for the Study and as a Text-book for the Use of Schools. Funk \& Wagnalls Company. 